\title{
IS6110 based amplityping assay and RFLP fingerprinting of clinical isolates of Mycobacterium tuberculosis
}

\author{
K Y Yuen, C M Chan, K S Chan, W C Yam, P L Ho, P Y Chau
}

\begin{abstract}
Aims-To evaluate the usefulness of two IS6110 based typing methods, an amplityping assay and restriction fragment length polymorphism (RFLP) analysis, for fingerprinting respiratory isolates of Mycobacterium tuberculosis.

Methods-For amplityping, a pair of primers which amplify the intervening sequence between the repetitive insertion sequence IS6110 was used to generate a banding pattern which was confirmed by hybridisation. This assay was compared with conventional chromosomal DNA RFLP typing in the evaluation of 110 epidemiologically diverse isolates.

Results-Polymerase chain reaction (PCR) amplityping generated a single pattern in Hong Kong Chinese strains, but two and four diverse patterns in Filipino and Vietnamese strains, respectively, and could be completed within four days. When compared with chromosomal DNA RFLP typing, which took three weeks to complete, four different RFLP patterns could be seen among the Chinese strains, while seven patterns were found in the Filipino and Vietnamese strains. No change in amplityping or RFLP patterns was found in 36 sequential isolates from the same patients after anti-tuberculosis treatment for up to 12 months, despite the emergence of resistance in three of these strains. No specific amplityping or RFLP pattern could be related to different patterns of drug susceptibility.

Conclusion-PCR amplityping could be used initially as a rapid typing method to distinguish strains originating from different localities. This could be important for investigation of outbreaks of tuberculosis-for example, in refugee camps.

(f Clin Pathol 1995;48:924-928)
\end{abstract}

Keywords: Mycobacterium tuberculosis, IS6110, amplityping, RFLP analysis, PCR

A good typing method is essential for tracking the transmission of Mycobacterium tuberculosis, identifying strains with peculiar resistance patterns or virulence, and studying the pathogenesis of the disease in terms of reinfection or reactivation. Many different markers such as biotype, phage type, antibiogram, restriction fragment length polymorphism (RFLP) pattern of chromosomal DNA after hybridisation with whole chromosomal $M$ tuberculosis DNA, ${ }^{1-4}$ and repetitive DNA elements, including IS6110, IS1081, 36 base pair direct repeat, polymorphic GC-rich repetitive sequence, major polymorphic tandem repeat and (GTG) 5 oligonucleotide, have been exploited as tools for strain differentiation..$^{5-7}$ The usefulness of producing strain specific DNA fingerprint patterns, especially that of IS6110, had been well documented in the investigation of many community or nosocomial outbreaks, laboratory cross-contamination and other epidemiological studies. ${ }^{8-12}$ Despite these encouraging results, these typing methods require the extraction of chromosomal DNA from a pure culture which is time-consuming and tedious. With the aim of expediting and simplifying the procedure for routine use in clinical laboratories, many PCR based modifications, including the use of mixed linker, unilateral nested, ligation mediated, arbitrarily primed and priming between copies of IS6110, were reported. ${ }^{13-17}$ However, few of these modified techniques have been evaluated in routine laboratories on clinical isolates and thus the possibility of replacing the more cumbersome IS6110 based chromosomal DNA RFLP typing with these newer techniques has not been explored fully.

\section{Methods}

As part of a follow up study of patients admitted to a chest hospital for treatment of pulmonary tuberculosis, ${ }^{18} 110$ strains of $M$ tuberculosis isolated over a three year period from 92 patients were selected for this study (table). Group 1A were Hong Kong residents who were born in diverse geographical regions outside Hong Kong from whom strains of $M$ tuberculosis were isolated sequentially. These strains were sensitive to all first line anti-tuberculosis agents. Patients in group 1B were similar to those in group 1A except that the isolates were resistant to one or more anti-tuberculosis agents. Group 2A were patients who resided in Hong Kong since birth and their isolates were sensitive to all first line anti-tuberculosis agents. Group 2B, also natives of Hong Kong, had a diverse antimicrobial susceptibility pattern which included strains resistant to two to seven drugs, including isoniazid, streptomycin, rifampicin, ethambutol, ofloxacin, kanamycin, and pyrazinamide. Group 3 patients were Filipino housemaids working in Hong Kong, while 
Oligonucleotide sequences

\begin{tabular}{llc}
\hline Oligonucleotide & Sequence & Location* $^{*}$ \\
\hline IS6110 probe & & $883-865$ \\
1 & 5'-CCTGCGAGCGTAGGCGTCGG & $762-781$ \\
2 & 5'-CTCGTCCAGCGCCGCTTCGG & $1311-1329$ \\
PCR fingerprinting primers & 5'-GGCTGAGGTCTCAGATCAG & $53-34$ \\
IS1 & 5'-ACCCCATCCTTTCCAAGAAC & $4-31$ \\
PCR fingerprinting probes & 5'-TGAACCGCCCCGGCATGTCCGGAGACTC & $1331-1358$ \\
$\quad$ Probe 1 & 5'-GAGTCTCCGGACTCACCGGGGCGGTTCA & \\
Probe 2 &
\end{tabular}

${ }^{*}$ Numbering is based on Thierry's system. ${ }^{18}$

those in group 4 were Vietnamese refugees. With the exception of group 4, all patients were unrelated epidemiologically. All eight patients in group 4 were from an open refugee camp, where they lodged at night. Thus, the strains were selected from a pool of isolates with a wide geographical, temporal and antimicrobial susceptibility spectrum in order to assess the discriminating potential of the typing techniques.

\section{BACTERIAL STRAINS}

These 110 strains of $M$ tuberculosis were isolated from 103 expectorated sputum, four bronchoalveolar lavage and three bronchial aspirate specimens. They were kept on Dorset egg medium at $4^{\circ} \mathrm{C}$. All isolates were identified as $M$ tuberculosis by growth rate, optimal growth temperature, colony morphology, and biochemical tests (niacin accumulation, nitrate reduction, $68^{\circ} \mathrm{C}$ semiquantitative catalase, thiophen-2 carboxylic acid hydrazide susceptibility, and pyrazinamidase).

BACTERIAL CULTIVATION AND DNA ISOLATION Two methods were used to isolate DNA from $M$ tuberculosis strains. For RFLP typing of chromosomal DNA, isolates were grown for two to four weeks at $37^{\circ} \mathrm{C}$ in $100 \mathrm{ml}$ Middlebrook $7 \mathrm{H} 9$ broth supplemented with Tween 80 , glycerol, and OADC complex (Becton Dickinson, Cockeysville, Maryland, USA) with constant shaking. Bacteria were collected by centrifugation. To render the bacterial cells more susceptible to further digestion and the extraction process, the cell pellet was washed with saturated cesium chloride (Boehringer Mannheim, Mannheim, Germany) solution containing 1\% Triton-X 100 (Sigma, St Louis, Missouri, USA) and subjected to osmotic shock with 30 volumes of sterile distilled water. The DNA was then extracted and purified as described previously. ${ }^{19}$

$M$ tuberculosis DNA cultured on LowensteinJensen solid medium was used for amplityping. The organisms were suspended in buffer containing lysozyme (Sigma) at a concentration of $1 \mathrm{mg} / \mathrm{ml}$ and incubated for one hour at $37^{\circ} \mathrm{C}$. After the addition of an equal volume of lysis solution $(0 \cdot 2 \mathrm{M} \mathrm{NaOH}, 1 \%$ sodium dodecyl sulphate, $1 \mathrm{M} \mathrm{NaCl}$ ), the suspension was heated at $95^{\circ} \mathrm{C}$ for 10 minutes and neutralised with $2 \mathrm{M}$ Tris solution ( $\mathrm{pH} 7$ ). DNA was extracted with phenol/chloroform/isoamyl alcohol (25:24:1), precipitated in absolute ethanol and washed with $70 \%$ ethanol.

\section{PCR AMPLITYPING}

The primers presented in the table were used to amplify the flanking regions of the IS6110 insertion sequence. ${ }^{17} \mathrm{PCR}$ was performed using an automated thermal cycler (Perkin Elmer) and all reaction buffers contained $10 \mathrm{mM}$ Tris/ $\mathrm{HCl}$ (pH 8.3), $50 \mathrm{mM} \mathrm{KCl}, 1.5 \mathrm{mM} \mathrm{MgCl}_{2}$, $0.2 \mathrm{mM}$ of each dNTP (Pharmacia, Uppsala, Sweden), $2 \cdot 5$ units Taq polymerase (U.S. Biochemical Corp., Cleveland, Ohio, USA), $1 \mu \mathrm{M}$ of each primer, and $100 \mathrm{ng}$ template DNA in a final volume of $100 \mu$ l. The amplification profile consisted of a denaturation step at $95^{\circ} \mathrm{C}$ for five minutes, followed by 35 cycles with denaturation at $95^{\circ} \mathrm{C}$ for one minute, primer annealing at $55^{\circ} \mathrm{C}$ for one minute, and extension at $72^{\circ} \mathrm{C}$ for one minute.

The PCR products were electrophoresed through $7 \cdot 5 \%$ polyacrylamide gels and stained with ethidium bromide. For definitive interpretation of the PCR fingerprinting pattern, the stained gels were then electroblotted onto Hybond-N + membranes (Amersham, Little Chalfont, UK) using a semi-dry transfer cell (Bio-Rad, Hercules, California, USA), as described by the manufacturer, and hybridised, respectively, at $65^{\circ} \mathrm{C}$ and $62^{\circ} \mathrm{C}$ separately with two digoxigenin $-3^{\prime}$ end labelled oligonucleotide probes (probes 1 and 2 ; table).

\section{CHROMOSOMAL RFLP TYPING}

Chromosomal DNA ( $3 \mu \mathrm{g})$ was digested for 18 hours at $37^{\circ} \mathrm{C}$ with 15 units of PstI (Pharmacia), which has no recognition site within the IS6110 element. PvuII (Pharmacia) was also used for confirmation. The digested fragments were separated by electrophoresis through $0.75 \%$ agarose. The DNA was blotted onto a Hybond$\mathrm{N}$ membrane filter hybridised to a PCR generated digoxigenin labelled probe representing positions 762 to 883 of the IS6110 insertion sequence. $^{20}$ The targets were detected by chemiluminescence (DIG Luminescence Detection Kit, Boehringer Mannheim).

\section{Results}

Using chromosomal DNA RFLP typing, strains from Hong Kong Chinese had a consistent pattern which clearly differed from those of Vietnamese and Filipinos (figure, panel A). The minor band differences reflect occasional transposition events. ${ }^{3}$ Only four patterns could be identified in 79 Chinese isolates whereas seven patterns could be distinguished in 13 Filipino and Vietnamese isolates. The RFLP pattern did not differ greatly between strains 

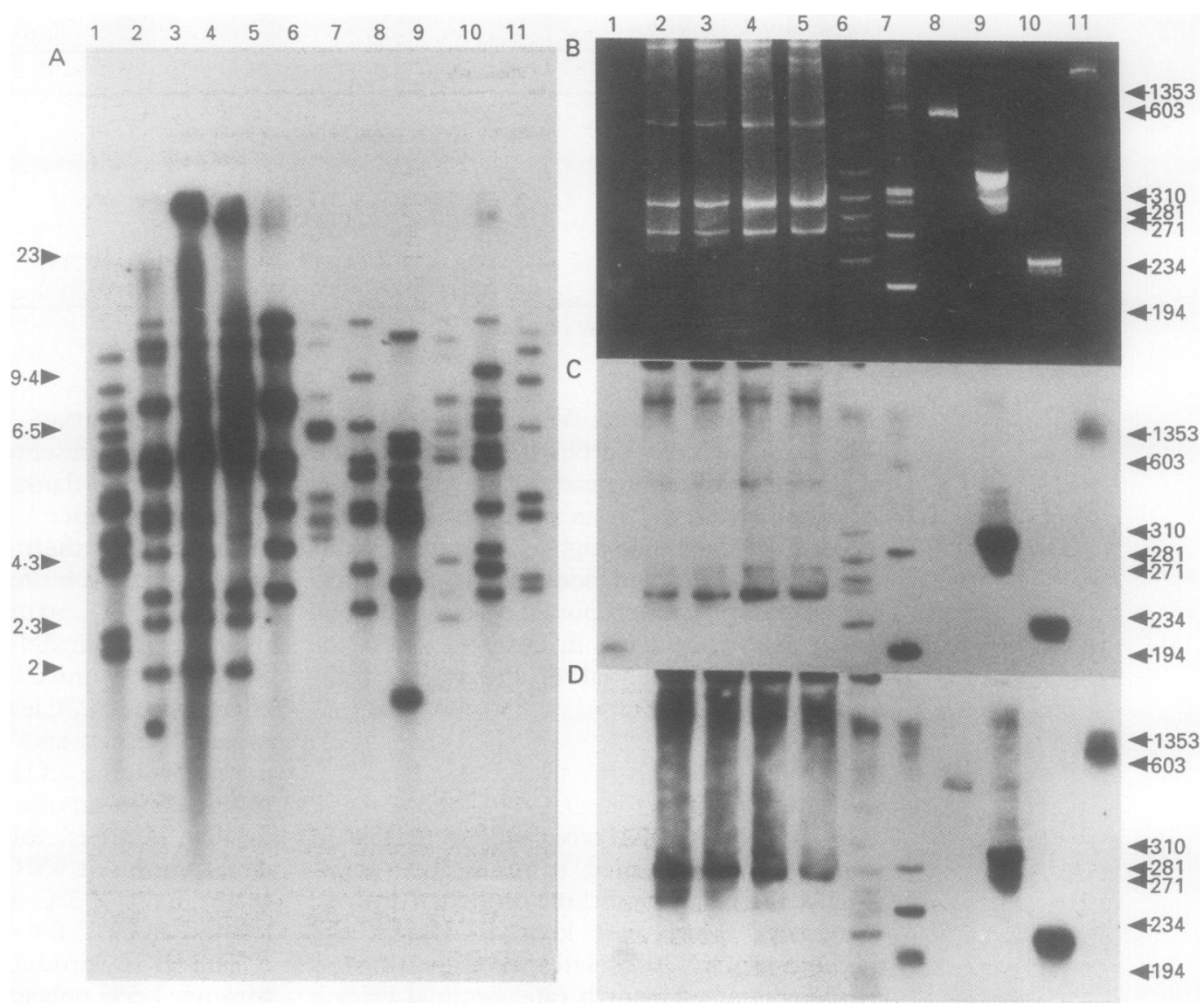

DNA typing by (A) chromosomal RFLP analysis and (B) PCR amplityping. The PCR products were resolved by polyacrylamide gel electrophoresis. After electroblotting, the PCR products were hybridised separately with probes 1 (C) and 2 (D). Lane 1, H37RV; lanes 2-5, four sub-strains from local isolates; lanes 6 and 7, two exogenous isolates from cases 80 and 81, both Filipinos; lanes 8-11, four exogenous isolates from cases 89-92, all Vietnamese.

with different antimicrobial resistance patterns and those which acquired antimicrobial resistance during therapy. The interval between the initial and subsequent isolation was between one and 12 months (groups $1 \mathrm{~A}$ and $1 \mathrm{~B}$ ). The RFLP patterns of strains isolated from group 2 patients did not differ greatly from those of group 1 patients. The following restriction fragments were found in most Chinese, four Vietnamese and three Filipinos: $2 \cdot 1$, $2 \cdot 7,3 \cdot 9,4 \cdot 5,5 \cdot 7,6,6 \cdot 3,8 \cdot 2,11 \cdot 2$, and $13 \cdot 5$ kilobases. Fifteen hybridised restriction fragments between 1.7 and 9.8 kilobases in length were unique to Vietnamese strains. Strains isolated from cases $80,81,89,90,91$, and 92 had very different RFLP patterns to those isolated from the Chinese patients (figure, panel $\mathrm{A}$, lanes 6-11). Four of these patients had a history of pulmonary tuberculosis, acquired while resident in the Philippines (one patient) and Vietnam (three patients). The number of copies of IS6110 present in these 110 strains of $M$ tuberculosis varied from seven to 15 , with a mean of 13. The average number of copies of IS6110 in Hong Kong strains was 13.2 while this figure was 8.7 in the Vietnamese and Filipino strains.

The findings for IS6110 based PCR amplityping were very similar to those achieved with chromosomal RFLP typing. In fact, all Hong Kong Chinese isolates had three bands on hybridisation, 240,268 and 410 base pairs in length (figure, panels $C$ and $D$, lanes 2-5) and their patterns are quite different from those observed in the strains isolated from the Filipino and Vietnamese patients who may have acquired tuberculosis outside Hong Kong (figure, panels $\mathrm{C}$ and $\mathrm{D}$, lanes 6-11). There were many other different bands present after gel electrophoresis in $15 \%$ of the PCR reactions but these bands were not detected after hybridisation (figure, panels $\mathrm{B}, \mathrm{C}$ and $\mathrm{D}$, lanes 6-11). Overall, two patterns could be found in Filipino strains and four in Vietnamese strains.

Chromosomal RFLP typing takes three to four weeks to complete while amplityping takes only four days, including hybridisation. Although six Chinese strains had nine to 11 copies of the IS6110 insertion sequence on amplityping, they exhibited the same three band pattern as the other Chinese strains after hybridisation.

\section{Discussion}

Despite improving nutrition, a good BCG vaccination programme and the availability of several effective antimicrobial agents against $M$ tuberculosis, tuberculosis remains a significant cause of morbidity and mortality in Hong Kong. With an annual notification of about 
6000 cases in 1993, the incidence of tuberculosis in Hong Kong, which is 100 cases per 100000 head of population, greatly exceeds the rate of 7 or less per 100000 reported for other developed countries. ${ }^{21}$ Such a high rate is quite unexpected in Hong Kong because it has provided a comprehensive supervised therapy regimen for all patients diagnosed with tuberculosis and a good contact tracing programme. This indicates that there are other factors present which facilitate disease transmission. Hong Kong is one of the most densely populated areas in the world with six million people crowded into 1760 square kilometres. This situation has been sustained and further exacerbated in recent years by the influx of migrants from neighbouring countries, especially Mainland China, Vietnam and the Philippines. Furthermore, the incidence of HIV infection is increasing and $16 \%$ of patients with AIDS also have tuberculosis. Thus, Hong Kong is a unique setting for the evaluation of various typing methods for the epidemiological investigation of tuberculosis. Previous typing methods, including biotyping, antibiogram and phage typing, are either inefficient or do not discriminate sufficiently between strains. $^{12}$ RFLP analysis is increasingly being used to type $M$ tuberculosis utilising whole chromosomal DNA probes and strain specific repetitive DNA markers, such as IS6110 (986) and IS1081, a major polymorphic tandem repeat. ${ }^{46811}$ In this study, we have compared the validity of IS6110 based chromosomal RFLP analysis and rapid PCR amplityping in a routine clinical laboratory. By comparing strain variability and epidemiological data, the usefulness of these typing methods for studying the transmission of tuberculosis could be ascertained.

Many different bands were found on gel electrophoresis after IS6110 based PCR amplityping; however, a three banded pattern only was present in all 80 Chinese strains after hybridisation. This indicates that hybridisation is important to offset non-specific amplification which could still occur in PCR amplityping despite stringent amplification conditions. We found that the number of bands observed on polyacrylamide gel electrophoresis was higher using the reported magnesium concentration ${ }^{17}$ but these disappeared after hybridisation. Furthermore, the reproducibility of these bands was very poor when the test was repeated with different batches of this mastermix under the same amplification conditions using the same thermal cycler. Our results also suggest that only four of the many copies of IS6110 present in these strains are consistently close enough to amplified. The more encouraging finding was that all of the isolates from Filipino or Vietnamese patients who contracted tuberculosis in their native country had a different PCR banding pattern. Moreover, strains from the two Vietnamese patients born in Hong Kong had the same PCR banding pattern, and very similar chromosomal RFLP patterns, as other Chinese strains. However, while the PCR amplityping assay is faster and easier to perform, it is definitely less discriminatory than the conventional technique.
Four RFLP patterns were observed in the 80 Chinese strains and the number of copies of IS6110 found in these strains varied from nine to 15 , despite the rather conserved banding pattern. There was no correlation between the RFLP pattern and antimicrobial susceptibility. There was no change in RFLP pattern between the initial and subsequent strains even in those which acquired antibiotic resistance. This is in agreement with in vitro studies which demonstrated the stability of the fingerprint pattern despite emerging drug resistance. ${ }^{3}$ This finding suggests that drug resistance arose as a result of spontaneous DNA mutations which were not reflected in the RFLP pattern.

When the results presented here are compared with those of Das et al, ${ }^{22}$ two different patterns are evident: $11 \%$ of their post-treatment strains had noticeably different RFLP patterns when compared with the pre-treatment strains. Their collection of strains also had a more diverse RFLP pattern with zero to 23 (median 19) copies of IS6110. These results probably arose because Das et al used strains collected over 15 years ago. Our findings suggest that the $M$ tuberculosis genotype has now become more homogeneous, indicating that routes of transmission may have changed in the recent years. Fifteen years ago, transmission of $M$ tuberculosis usually occurred in the home or work place. Since then Hong Kong has become more affluent and air conditioning more widespread. Moreover, the managing companies of these facilities tried to cut down the cost of electricity by increasing the percentage of recirculated air. This could have contributed to the spread of certain strains of $M$ tuberculosis and therefore to low genotypic diversity, as reported in another study. ${ }^{12}$ The low diversity of the IS6110 based chromosomal RFLP pattern makes it less useful as a typing method for tracing local transmission and therefore other markers and methods need to be evaluated.

Some of this work was carried out by $\mathrm{Mr}$ C M Chan for partial fome of this work wapported by fulfilment of the research grants from the Committee on Research and Conference Grants, The University of Hong Kong, and the Research Grant Council (Grant No. HKU 333/93M), Hong Kong.

1 Hoffner SE, Svenson SB, Norberg R, Dias F, Ghebremichael $S$, Kallenius G. Biochemical heterogeneity of Mycobacterium tuberculosis complex isolates in Guinea-Bissau. f Clin Microbiol 1993;31:2215-17.

2 Nolan CM, Elarth AM, Barr H, Saeed AM, Risser DR. An out-break of tuberculosis in a shelter for homeless men. Am Rev Respir Dis 1991;143:257-61.

3 van Soolingen D, Hermans PWM, de Haas PEW, Soll DR, van Embden JD. Occurrence and stability of insertion, van Embden ex strains: insertion sequence-dependent polymorm as a tool in the epidemiology of tuberculosis. f Clin Micmbiol 1991;29:2578-86.

4 Ross BC, Raios K, Jackson K, Sievers A, Dwyer B. Differentiation of Mycobacterium tuberculosis strains by use of a nonradioactive Southern

5 Thierry D, Cave MD, Eisenach KD, Crawford JT, Bates $\mathrm{JH}$, Gicquel B, et al. IS6110, an IS-like element of Mycobacterium tuberculosis complex. Nucleic Acids Res 1990; 18:188.

6 van Soolingen D, de Hass PEW, Hermans PWM, Groenen PM, van Embden JD. Comparison of various repetitive DNA elements as genetic markers for strain differentiation and epidemiology of Mycobacterium tuberculosis. $\mathcal{F}$ Clin Microbiol 1993;31:1987-95. 
7 Wiid IJ, Werely C, Beyers N, Donald P, van Helden PD. Oligonucleotide (GTG) 5 as a marker for Mycobacterium
tuberculosis strain identification. $\mathcal{F}$ Clin Microbiol 1994; tuberculosis

8 Daley LCL, Small PM, Schecter GF, Schoolnik GK, McAddam RA, Jacobs WR Jr, et al. An outbreak of tuberculosis with accelerated progression among persons infected with the human immunodeficiency virus-an analysis using restriction fragment-length polymorphism. $N$ Engl f Med 1992;326:231-5.

9 Jereb JA, Burwen DR, Dooley SW, Haas WH, Crawford JT, Geiter LJ, et al. Nosocomial outbreak of tuberculosis in a renal transplant unit: Application of a new technique for restriction fragment length polymorphism analysis of Mycobacterium tuberculosis isolates. F Infect Dis 1993; 168:1219-24

10 Small PM, McClenny NB, Singh SP, Schoolnik GK, Tompkins LS, Mickelsen PA. Molecular strain typing of Mycobacterium tuberculosis to confirm cross-contamination in the mycobacteriology laboratory and modification of procedures to minimise occurrence of falsepositive cultures. $\mathcal{F}$ Clin Microbiol 1993;31:1677-82.

11 Chevrel-Dellagi D, Abderrahman A, Haltiti R, Koubaji H, Gicquel B, Dellagi K. Large-scale DNA fingerprinting of Mycobacterium tuberculosis strains as a tool for epidemiological studies of tuberculosis. F Clin Microbiol 1993; 31:2446-50.

12 Godfrey-Faussett P, Stoker NG. Aspects of tuberculosis in Africa. 3. Genetic "fingerprinting" for clues to the pathogenesis of tuberculosis. Trans $R$ Soc Trop Med Hyg pathogenesis of tu

13 Hass WH, Butler WR, Woodley CL, Crawford JT. Mixedlinker polymerase chain reaction: a new method for rapid fingerprinting of isolates of the Mycobacterium tuberculosis complex. F Clin Microbiol 1993;31:1293-8.
14 Plikaytis BB, Crawford JT, Woodley CL, Butler WR, Eisenach KD, Cave MD, et al. Rapid, amplificationEisenach $\mathrm{KD}$, Cave $\mathrm{MD}$, et al. Rapid, amplificationGen Microbiol 1993;139:1537-42.

15 Palittapongarnpim P, Chomyc S, Fanning A, Kunimoto D. DNA fingerprinting of Mycobacterium tuberculosis isolates by ligation-mediated polymerase chain reaction. Nucleic Acid Res 1993;21:761-2.

16 Palittapongarnpim P, Chomyc S, Fanning A, Kunimoto D. DNA fragment length polymorphism analysis of Mycobacterium tuberculosis isolates by arbitrarily primed polymerase chain reaction. $\mathcal{f}$ Infect Dis 1993;167:975-8.

17 Ross BC, Dwyer B. Rapid, simple method for typing isolates of Mycobacterium tuberculosis by using the polymerase chain reaction. $₹$ Clin Microbiol 1993;31:329-34.

18 Yuen KY, Chan KS, Chan CM, Ho BSW, Dai LK, Chau PY, et al. Use of PCR in routine diagnosis of treated and untreated pulmonary tuberculosis. F Clin Pathol 1993;46: untreated pr. 22 .

19 Bose M, Chander A, Das RH. A rapid and gentle method for the isolation of genomic DNA from mycobacteria. Nucleic Acids Res 1993;21:2529-30.

20 Eisenach KD, Cave MD, Bates JH, Crawford JT. Polymerase chain reaction amplification of a repetitive DNA sequence specific for Mycobacterium tuberculosis. F Infect Dis 1990;161:977-81.

21 Department of Health, Hong Kong. Notification of infectious disease-recent changes. Hong Kong: Public Health and Epidemiology Bulletin, 1994;3:16.

22 Das S, Chan SL, Allen BW, Mitchison DA, Lowrie DB. Amplification of DNA fingerprinting with IS986 to sequential mycobacterial isolates obtained from pulmonary quential mycobacterial isolates obtained from pulmonary
tuberculosis patients in Hong Kong before, during and tuberculosis patients in Hong Kong before, during and
after short-course chemotherapy. Tubercle Lung Dis 1993; 74:47-51. 